\title{
Targeting of the leukemia microenvironment by c(RGDfV) overcomes the resistance to chemotherapy in acute myeloid leukemia in biomimetic polystyrene scaffolds
}

\author{
ZHAO-HUA SHEN ${ }^{1,2}$, DONG-FENG ZENG ${ }^{1}$, XIAO-YAN WANG $^{2}$, YING-YING MA $^{1}$, XI ZHANG $^{1}$ and PEI-YAN KONG ${ }^{1}$ \\ ${ }^{1}$ Department of Hematology, Xinqiao Hospital, The Third Military Medical University, Chongqing 400037; \\ ${ }^{2}$ Department of Gastroenterology, Third Xiangya Hospital, Central South University, Changsha, Hunan 410013, P.R. China
}

Received April 9, 2015; Accepted July 12, 2016

DOI: $10.3892 / \mathrm{ol} .2016 .5042$

\begin{abstract}
The bone marrow microenvironment provides a relative sanctuary from cytotoxic drugs for leukemia cells. The present niche models concentrate on a two-dimensional (2D) co-culture system in vitro, which does not imitate the in vivo environment, while the 3D scaffolds are more reflective of this. Osteopontin (Opn) secreted by bone marrow osteoblasts, may participate in protecting leukemia cells from apoptosis by binding to its receptor $\alpha v \beta 3$, which can be expressed on the surface of the leukemia MV4-11 cell line. However, the association between the Opn/ $\alpha v \beta 3$ axis and leukemia cells is unknown. In the present study, experiments were conducted on 3D polystyrene scaffolds coated with osteoblasts and leukemia cells. The cells were exposed to cyclo(Arg-Gly-Asp-d-Phe-Val) [c(RGDfV)] (35 nmol/ml), which blocks $\alpha v \beta 3$, for a period of $24 \mathrm{~h}$. Cytarabine was applied $24 \mathrm{~h}$ later. The adhesion, migration and apoptosis rates, and the cell cycle of the leukemia cells were analyzed after incubation for 24 and $48 \mathrm{~h}$. In contrast to the 2D culture system, the stromal cells in the scaffolds secreted significantly more alkaline phosphatase and Opn $(\mathrm{P}<0.05)$. c(RGDfV) disrupted the adhesion and migration between the tumor cells and the matrix, induced the leukemia cells to leave the protective microenvironment and increased their sensitivity to cell cycle-dependent agents $(\mathrm{P}<0.05)$. In summary, the data certified that the 3D scaffolds are suitable for the growth of cells, and that c(RGDfV) inhibits the adhesion and migration abilities of leukemia cells in the endosteal niche. Therefore, blocking the function of Opn may be beneficial in the treatment of acute myeloid leukemia.
\end{abstract}

Correspondence to: Mrs. Pei-Yan Kong, Department of Hematology, Xinqiao Hospital, The Third Military Medical University, 183 Xinqiao Street, Shapingba, Chongqing 400037, P.R. China

E-mail: peiyankong@aliyun.com

Key words: endosteal niche, Opn, three-dimensional culture system, c(RGDfV)

\section{Introduction}

Schofield introduced the concept of the hematopoietic stem cell (HSC) niche in 1978 (1). The niche contains the endosteal niche and the vascular niche. The endosteal niche is a prominent compartment of the HSC niche and it assists HSCs to maintain the quiescent state under normal conditions. The pathological niche of leukemia models promotes leukemia stem cell (LSC) proliferation, survival and protects LSCs from the killing effects of chemotherapeutic drugs. The osteoblast niche becomes the region for the settlement and proliferation of certain leukemia cells, particularly the stem cells (2). Despite the uncontrolled growth and survival features, the majority of primary acute myeloid leukemia (AML) cells rely on the microenvironment, which may be a targetable weakness (3).

Future studies should assess the effect of an abnormal niche on the biological characteristics of leukemia cells and investigate the mechanism of interaction between the bone marrow microenvironment and leukemia cells. These studies may promote the treatment of leukemia. The conventional in vitro two-dimensional (2D) co-culture system does not reproduce the in vivo microenvironment (4). However, cells maintained in spatial distribution can mimic the complex, cellular organization of the bone marrow microenvironment. The 3D culture system has been used compellingly in recent years (5).

Osteopontin (Opn) is a negatively charged phosphorylated glycoprotein that is secreted by osteoblasts. The overexpression of Opn is a feature of hematologically malignant tumors. Opn is the key factor that induces HSCs and leukemia cells to stay in the endosteal niche (6) and maintain the G0 phase. Integrin $\alpha v \beta 3$ is a membrane receptor protein that can recognize a key structure of Opn, namely the RGD sequence. The combination of the two proteins can play a vital role in tumor cell adhesion, migration, invasion and tumor angiogenesis (7). If the domain structure of $\alpha v \beta 3$ has defects or mutations, it will lead to loss of promoting adhesion function. Due to its high expression in tumor cells and its low expression in normal cells, integrin $\alpha v \beta 3$ may be an ideal target for tumor therapy. There is no evidence that cyclo(Arg-GlyAsp-d-Phe-Val) [c(RGDfV)], which blocks $\alpha v \beta 3$, can mobilize leukemia cells to the peripheral blood, and it is not clear whether $\mathrm{c}(\mathrm{RGDfV})$ can increase the sensitivity of the leukemia cells to chemotherapy drugs after disrupting the microenvironment. 
The present study mainly clarified the following: i) How a 3D culture system compared with the common 2D culture system; ii) the effect of c(RGDfV) on the adhesion function of the endosteal niche; iii) the effects of $c($ RGDfV) on leukemia cell apoptosis and the cell cycle; and vi) the changes in leukemia cell sensitivity to cytarabine (Ara-C) following the administration of the drug.

\section{Materials and methods}

Materials and reagents. The monoclonal mouse anti-human $\alpha v \beta 3$-fluorescein isothiocyanate (FITC; catalog no. 336403), cluster of differentiation (CD)34-FITC (catalog no. 343603), CD45-phycoerythin (PE; catalog no. 368509), CD90-FITC (catalog no. 328107) and CD105-PE (catalog no. 323205) antibodies were obtained from BioLegend Inc., (San Diego, CA, USA). Test size products are transitioning from 20 to $5 \mu \mathrm{l}$ per test. The suggested use of this reagent for flow cytometry is per million cells in $100 \mu \mathrm{l}$ staining volume. $\mathrm{c}(\mathrm{RGDfV})$ was provided by GL Biochem (Shanghai) Ltd. (Shanghai, China). Human mesenchymal stem cell (MSC) osteogenic differentiation medium was provided by Cyagen Biosciences, Inc. (Santa Clara, CA, USA), and contained basal medium, ascorbate, b-glycerosphophate and dexamethasone; these components were also purchased individually from Sigma-Aldrich (St. Louis, MO, USA). Dulbecco's modified Eagle's medium (DMEM)/F12 medium, RPMI 1640 medium, trypsin and fetal bovine serum (FBS) were purchased from GE Healthcare Life Sciences (Hyclone; Logan, UT, USA). A human Opn enzyme-linked immunosorbent assay (ELISA) kit was purchased from R\&D Systems (Minneapolis, MN, USA). The Transwell Insert system for the migration assay was purchased from BD Biosciences (Bergen, NJ, USA) The Cell Cycle Analysis kit and BCECF-AM were provided by Beyotime Institute of Biotechnology (Haimen, China). The Annexin V-FITC apoptosis detection kit was obtained from BD Pharmingen (San Diego, CA, USA).

Patient cells. In total, 10 AML (M5) samples from the bone marrow of AML patients at the time of preliminary diagnosis were acquired after obtaining written informed consent. Patients were enrolled between March and October 2013 from the Department of Hematology of Xinqiao Hospital, The Third Military Medical University (Chonqing, China). Ethical approval for this study was provided by the Medical Ethics Committee of Xinqiao Hospital (The Third Military Medical University). For the culture of osteoblasts, bone marrow aspirates underwent Ficoll-Paque gradient centrifugation (Tianjin Hao Yang Biological Products Technology Co., Ltd., Tiajin, China) at $400 \mathrm{x}$ g for $20 \mathrm{~min}$. After two passages, the human MSC osteogenic differentiation medium was used as previously described (8). FLT3-internal tandem duplication (ITD)-positive leukemia MV4-11 cells were obtained from the American Type Culture Collection (Manassas, VA, USA) and cultured in complete RPMI 1640 medium at $37^{\circ} \mathrm{C}$ in a humidified environment with $5 \% \mathrm{CO}_{2}$ and the cells began with passage every 2 days.

Isolation and culture of human MSCs. Samples of $\sim 5 \mathrm{ml}$ of heparinized bone marrow were collected from the AML patients at the preliminary diagnosis after obtaining written informed consent. The mononuclear cell fraction was isolated by density gradient centrifugation on Ficoll-Hypaque (density, $1.077 \mathrm{~g} / \mathrm{cm}^{3}$ ) and cultured in DMEM/F12 supplemented with $10 \%$ FBS. After two passages, the cells were identified and used for osteodifferentiation.

Biomimetic osteoblast niche. For the 3-dimensional (3D) scaffolds, MSCs that had been passaged twice were digested with $0.25 \%$ trypsin and re-suspended in medium. A total of $6.5 \times 10^{4} \mathrm{MSCs}$ in $60 \mu$ losteoinductive culture medium containing $10^{-8} \mathrm{~mol} / \mathrm{l}$ dexamethasone, $10 \mathrm{mmol} / 1 \beta$-glycerophosphate and $50 \mu \mathrm{g} / \mathrm{ml}$ retinoic acid was dripped into the wells of 24-well plates. The cell-seeded scaffolds were put into the incubator for $3 \mathrm{~h}$ prior to adding another $940 \mu \mathrm{l}$ of fresh medium. Additionally, $1.2 \times 10^{4}$ MSCs were cultured without scaffolds in the 24-well plates to accord with the same cell seeding density (number of cells $/ \mathrm{cm}^{2}$ ). The medium was changed twice every week. The cells were identified after 3 weeks. Alizarin red staining and alkaline phosphatase (ALP) staining were conducted for the identification of osteoblasts. Positive staining results demonstrated that the cells were cultured successfully.

Electron microscopy. The cells were cultured and fixed in $2.5 \%$ glutaraldehyde in a $4^{\circ} \mathrm{C}$ refrigerator overnight, and then the samples were dehydrated in a graded series of ethanol, air-dried and gold sputtered. The cells were analyzed using a KYKY-EM3200 scanning electron microscope (KYKY Technology Development, Inc., Beijing, China).

Measurement of Opn and ALP levels in osteoblast supernatant. Supernatant was collected on the 7 th, 14th and 21 st days following the culture of the cells, and they were analyzed using a human OPN ELISA kit, according to the manufacturer's instructions. Various known concentrations of standard solution $(50 \mu \mathrm{l})$, to generate the standard curve, or $40 \mu \mathrm{l}$ samples plus $10 \mu \mathrm{l}$ sample diluent were added into each hole. Next, $50 \mu 1$ horseradish peroxidase-labeled detection antibody was added into the sample standard bore holes for $60 \mathrm{~min}$. The liquid was then discarded, and $50 \mu \mathrm{l}$ each of substrate A and $\mathrm{B}$ (visualization reagents from the ELISA kit) were mixed and incubated for $15 \mathrm{~min}$ in the dark. Finally, stop solution was added into each hole and the optical density value was measured using a microplate reader. Besides, the supernatant was collected when cells were cultured at the 7th, 14th and 21st days, and $1 \mathrm{ml}$ of $2 \%$ Triton X-100 was added to the cells for long-term refrigeration. Next, the lysate $(100 \mu \mathrm{l})$ was added to a 96-well plate, then use the ALP kit to test the activity of ALP.

Group of experiments. Once the osteoblasts had been cultured successfully, they were cultured in RPMI 1640 medium for 2 days. MV4-11 cells ( $1.8 \times 10^{5}$ cells $/ \mathrm{ml}$ in the $2 \mathrm{D}$ culture system and $1 \times 10^{6}$ cells $/ \mathrm{ml}$ in the $3 \mathrm{D}$ culture system) were co-cultured with leukemia osteoblasts in RPMI 1640 medium. The experiments used two groups: The experimental group received $\mathrm{c}(\mathrm{RGDfV})(35 \mathrm{nmol} / \mathrm{ml})$ and the control group received an equal volume of phosphate-buffered saline (PBS) only.

Adhesion test by fluorometric assay. MV4-11 cells $\left(1.8 \times 10^{5}\right.$ cells $/ \mathrm{ml}$ in the $2 \mathrm{D}$ culture system and $1 \times 106$ cells $/ \mathrm{ml}$ in the 3D culture system) were prelabeled with BCECF-AM $(3 \mu \mathrm{M})$, mixed with $\mathrm{c}(\mathrm{RGDfV})$ and co-cultured with osteoblasts for 
$4 \mathrm{~h}$ at $37^{\circ} \mathrm{C}$. Non-adherent cells were washed away using PBS three times, and images of the adherent cells were captured prior to fluorescence intensity being measured.

Flow cytometric analyses of $\alpha v \beta 3$ expression. To analyze the expression of $\alpha \mathrm{v} \beta 3$ surface markers on the leukemia cells prior to and after co-culture with osteoblasts, the cells were stained with a mouse anti-human monoclonal $\alpha v \beta 3$-FITC antibody. The expression of the surface antigens was analyzed using a flow cytometer.

Transwell migration assay. Osteoblasts were suspended in 24 -well plates. When the osteoblasts reached $80 \%$ confluence, untreated or c(RGDfV)-treated MV4-11 cells were seeded in the upper chamber of the Transwell inserts. After a 4-h incubation, the stromal layer containing cells that had migrated was carefully washed twice with PBS and counted.

Detection of in vitro apoptosis and cell cycle analysis. The leukemia cells were seeded alone, or with osteoblasts in the 2D or 3D culture system. The cells were then treated with $35 \mathrm{nmol} /$ $\mathrm{ml} \mathrm{c}(\mathrm{RGDfV})$ for $24 \mathrm{~h}$. Next, Ara-C $(0.02,0.2$ and $2 \mu \mathrm{g} / \mathrm{ml})$ was applied for $24 \mathrm{~h}$. The cells $\left(1 \times 10^{6}\right)$ were then washed. A double staining method with Annexin V-FITC/propdium iodide (PI) was used for the detection of in vitro apoptosis. Annexin V-FITC and propidium iodide (PI) were added, and the cells were incubated for $15 \mathrm{~min}$ at $4^{\circ} \mathrm{C}$. The cells were washed and analyzed for apoptosis with the use of flow cytometry. PI staining was also used to detect the levels of DNA in order to assess cell cycle distribution. The cells $\left(1 \times 10^{6}\right)$ were gathered and washed with PBS, and were fixed with $75 \%$ ethanol prior to the addition of $50 \mu \mathrm{g} / \mathrm{ml}$ PI. The cell cycle distribution was analyzed by flow cytometry.

Statistical analysis. Data were analyzed using SPSS software version 17.0 (Chicago, IL, USA). Student's t-test was used for comparisons between two groups and an analysis of variance was used for multiple comparisons. $\mathrm{P}<0.05$ was considered to indicate a statistically significant difference.

\section{Results}

Cell culture, osteogenic differentiation of MSCs and the different growth conditions in the $2 D$ and $3 D$ culture systems. MSCs were obtained from the bone marrow of leukemia patients and cultured (Fig. 1A). The cells were identified successfully as CD90- and CD105-positive, but CD34- and CD45-negative. Next, the MSCs underwent ossification induction and identification (Fig. 1B-D) In the PS scaffolds, interconnected networks of pores were observed upon scanning microscopy. The cells gradually became spindled after they were seeded on the scaffolds. The cells adhered on the inner surfaces of the scaffolds, and the compatibility between the cells and the material was good (Fig. 1E). SEM revealed that the cells were adhered on the scaffolds tightly (Fig. 1F). After the MV4-11 cells were added, the cells stretched out long tentacle-like pseudopods to contact with the osteoblasts in the niches (Fig. 1G), while the cells in the 2D system were flat and produced less extracellular matrix (Fig. 1H).

To detect the level of ALP expression, ELISA was used for the supernatant samples. For the 2D and 3D culture systems, the
ALP level increased with the culture period (Fig. 1I). In the 2D culture system, if the relative ALP activity of the 7th day was $100 \pm 10 \%$, that of the 14 th day was $130 \pm 10 \%$ and that of the $21 \mathrm{st}$ day was $132 \pm 3 \%$. In the $3 \mathrm{D}$ culture system, the relative activity of the 7 th day was $135 \pm 5 \%$, that of the 14 th day was $172 \pm 12 \%$ and that of the 21 st day was $168 \pm 7 \%$. The activity of Opn was also assessed and similar effects were found. In the 2D culture system, if the relative Opn activity of the 7th day was $100 \pm 18 \%$, that of the 14th day was $148 \pm 10 \%$ and that of the 21 st day was $146 \pm 17 \%$. In the $3 \mathrm{D}$ culture system, the relative activity of the 7 th day was $135 \pm 8.6 \%$, that of the 14 th day was $191 \pm 10 \%$ and that of the 21 st day was $190 \pm 10 \%$. MSCs differentiated into osteoblasts, which was accompanied with the rise of Opn levels. These experiments indicated that the Opn level reached its highest level at 14 days and then began to level off (Fig. 1J). The 3D scaffolds were determined to be more suitable for cell growth.

$c(R G D f V)$ induces disruption of leukemia cell migration and adhesion to leukemia osteoblasts in the $3 D$ and $2 D$ culture systems. As shown in Fig. 2A and B, the adhesion index of $\mathrm{c}(\mathrm{RGDfV})$ in the scaffolds was $52 \pm 12 \%$ compared with that of the control group $(\mathrm{P}<0.05)$. The migration index of $\mathrm{c}(\mathrm{RGDfV})$ in the scaffolds was $70 \pm 8 \%$ compared with that of the control group $(\mathrm{P}<0.05)$ (Fig. 2C). c(RGDfV) induced the disruption of leukemia cell migration in the 3D culture systems (Fig. 2D). The adhesion and migration of the 2D culture system was similar to that of the 3D culture system. In the in vitro studies, c(RGDfV) did not affect the level of Opn (Fig 2E). The MV4-11 cells exhibited the expression of $\alpha v \beta 3$ (Fig. 2F).

$c(R G D f V)$ has distinct effects on the cell cycle. In the present study, the leukemia osteoblasts induced the cell cycle arrest of the MV4-11 cells in the G0/G1 phase $(69.67 \pm 3.2 \%$ in the $3 \mathrm{D}$ scaffolds, $57.26 \pm 2.05 \%$ in the $2 \mathrm{D}$ culture system and $50.53 \pm 1.36 \%$ in the system in which the cells were cultured alone) $(\mathrm{P}<0.001$ for the $3 \mathrm{D}$ versus $1 \mathrm{D}$ culture system; $\mathrm{P}=0.012$ for the $2 \mathrm{D}$ versus $1 \mathrm{D}$ culture system). $\mathrm{c}(\mathrm{RGDfV})$ did not affect the percentage of cells in the G0/G1 phase (phase rate) when leukemia cells were cultured alone. $\mathrm{c}(\mathrm{RGDfV})$ induced the cells to enter the cycle in the presence of osteoblasts in the 2D and $3 \mathrm{D}$ culture systems. In the 2D culture system, G0/G1-phase rates induced by the $\mathrm{c}(\mathrm{RGDfV})$ and control groups were $43.39 \pm 1.51$ and $57.26 \pm 2.05 \%$, respectively $(\mathrm{P}=0.013)$. The $\mathrm{S}$-phase rates were $42.81 \pm 2.02$ and $32.33 \pm 2.08 \%$, respectively $(\mathrm{P}=0.003)$. In the $3 \mathrm{D}$ culture system, the $\mathrm{G} 0 / \mathrm{G} 1$-phase rates induced by the $\mathrm{c}(\mathrm{RGDfV})$ and control groups were $52.92 \pm 4.88$ and $69.67 \pm 3.2 \%$, respectively $(\mathrm{P}=0.008)$. The S-phase rates were $27.82 \pm 2.01$ and $23.79 \pm 1.69 \%$, respectively $(\mathrm{P}=0.045)$. The $3 \mathrm{D}$ culture system had a higher arrest effect on MV4-11 compared with that of the 2D culture system (Fig. 3).

$c(R G D f V)$ overcame drug resistance induced by osteoblasts in Co-culture with leukemia cell lines. To investigate the effects of osteoblast cells on the apoptotic potential of MV4-11 cells, co-cultured leukemia cells were stained and measured by flow cytometry. Fig. 4 shows that $\mathrm{c}$ (RGDfV) increased the apoptosis rate induced by Ara-C in the absence of leukemia osteoblasts, while in the presence of leukemia osteoblasts, the apoptosis rate of the leukemia cells decreased. The percentage of apoptotic cells was significantly decreased to $2.6 \pm 0.55 \%$ 

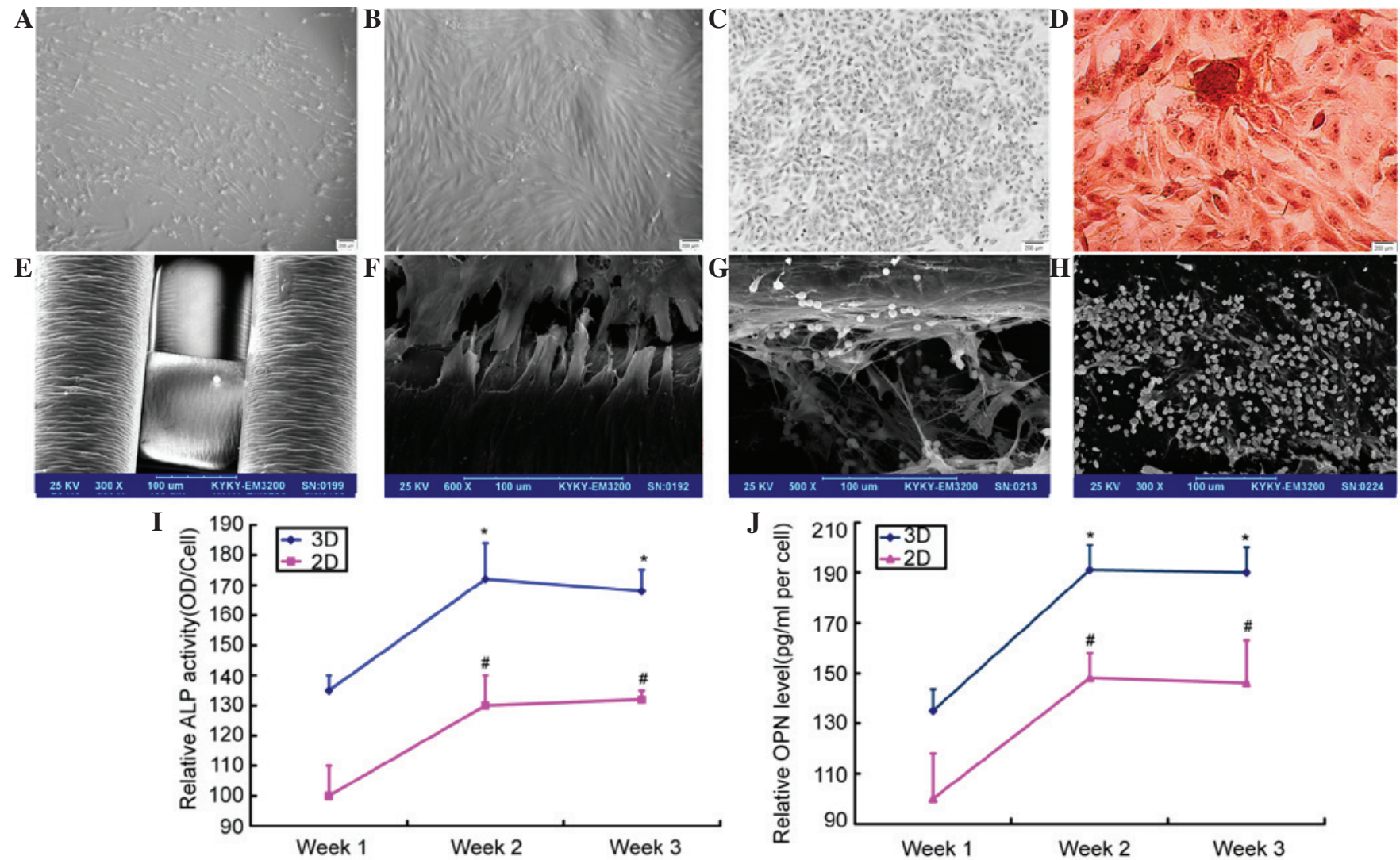

Figure 1. MSCs derived from acute myeloid leukemia patients were induced to form osteoblasts in vitro. (A) The morphology of the MSCs. (B) The morphology of the osteoblasts. (C) The cell identification was conducted by ALP staining. (D) The cells were identified by alizarin red staining. (E and F) The shape of the scaffolds and the osteoblasts seeded on the scaffolds. ( $\mathrm{G}$ and H) The co-culture of the leukemia cells and osteoblasts in the 3D and 2D culture systems. (I and J) The levels of ALP and OPN increased, and the levels were higher in the scaffolds." $\mathrm{P}<0.05$ compared with the control group of the $3 \mathrm{D}$ system. ${ }^{\text {" }} \mathrm{P}<0.05$ compared with the control group of the 2D system. MSC, mesenchymal stem cell; 3D, 3-dimensional; ALP, alkaline phosphatase; OPN, osteopontin; OD, optical density.

A

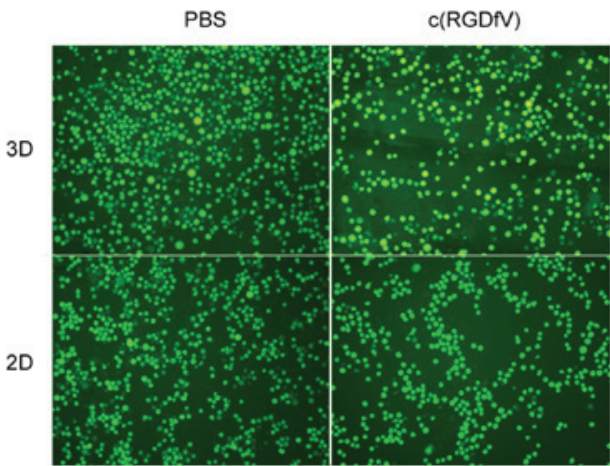

D

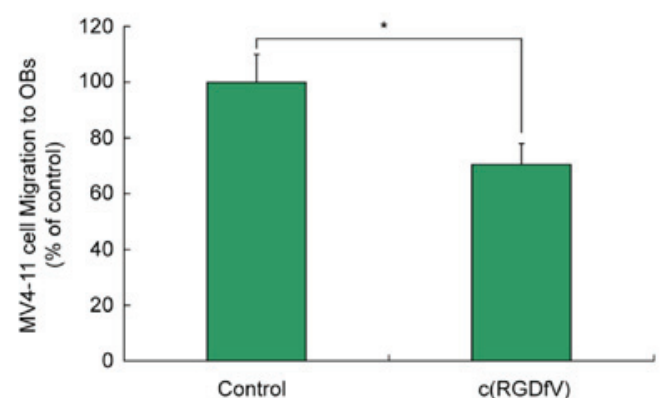

B

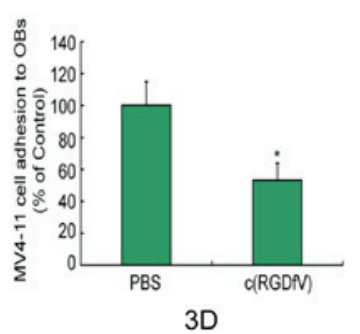

$\mathbf{E}$

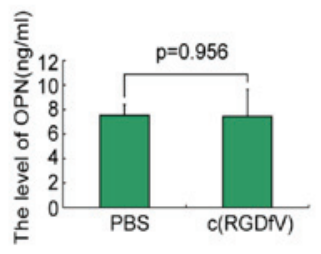

C

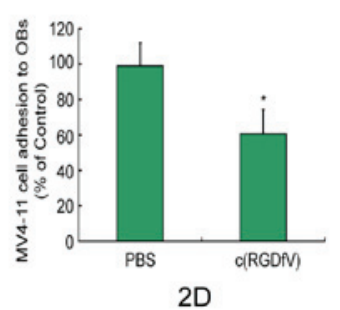

$\mathbf{F}$

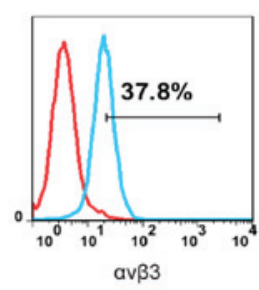

Figure 2. $c($ RGDfV) induces disruption of leukemia cell migration and adhesion in the 3D and 2D culture systems. (A) Fluorescence images of the adhesion between leukemia cells and osteoblasts following $\mathrm{c}(\mathrm{RGDfV})$ treatment in the $3 \mathrm{D}$ and $2 \mathrm{D}$ culture systems. Investigation of the effects of $\mathrm{c}(\mathrm{RGDfV})$ on the interaction between leukemia cells and osteoblasts indicated that $\mathrm{c}(\mathrm{RGDfV})$ inhibited adhesion in (B) 2D and (C) 3D culture systems; (D) migration was also inhibited in 3D cultures. (E) c(RGDfV) exhibited no effect on the level of OPN. (F) av 33 was expressed on the surface of the MV4-11 cells (37.8\%). 3D, 3-dimensional; PBS, phosphate-buffered saline; OB, osteoblast; OPN, osteopontin. * $\mathrm{P}<0.05$. 
A
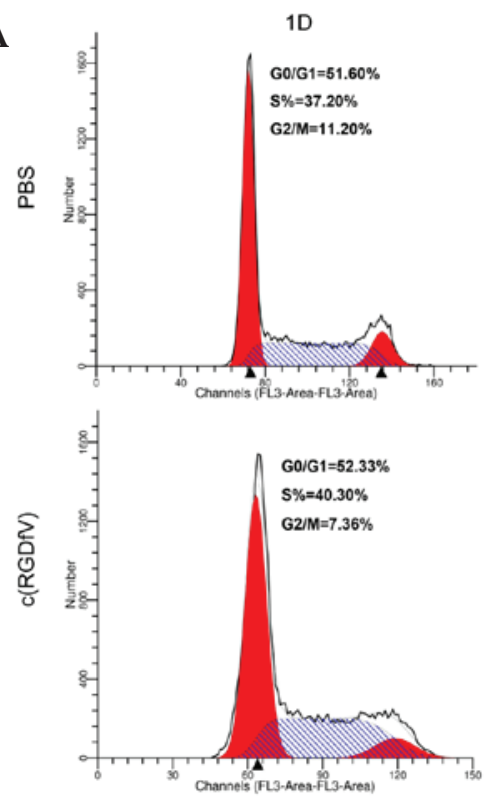

B

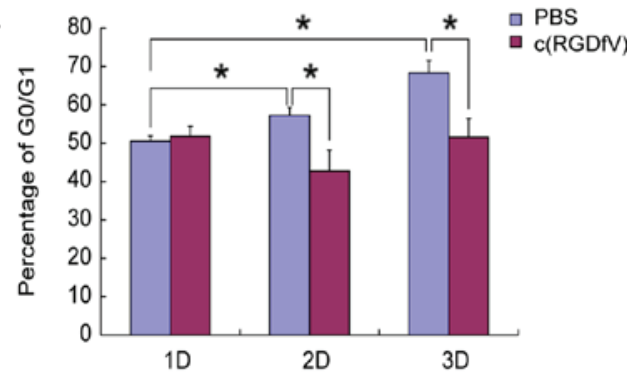

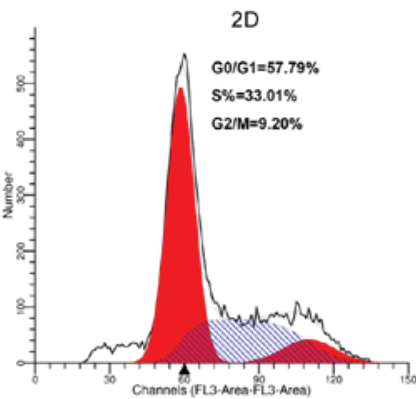
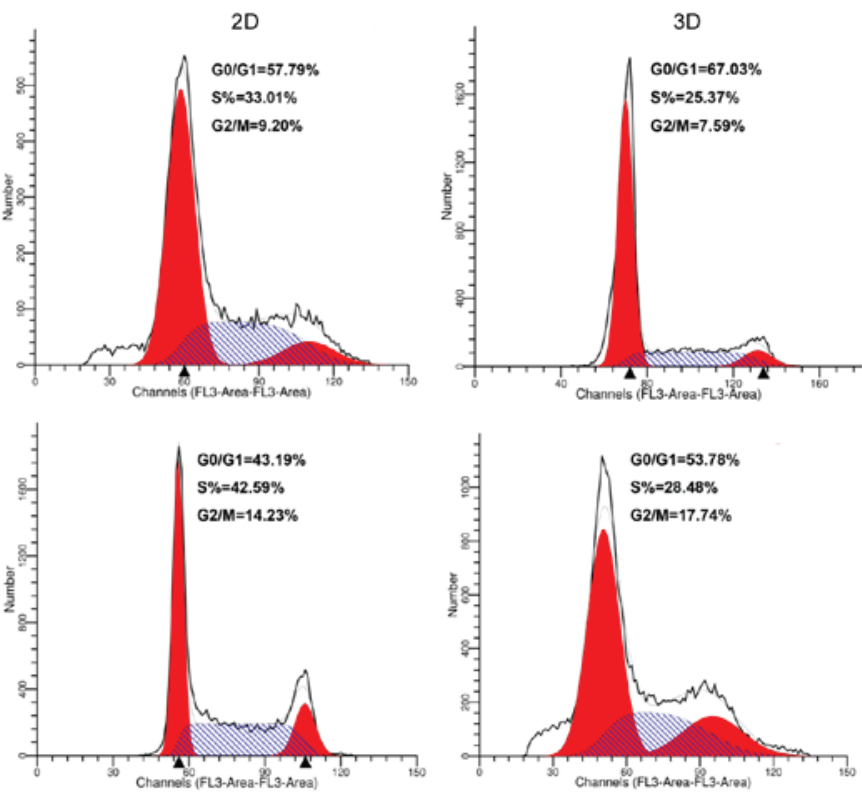

$\mathbf{C}$

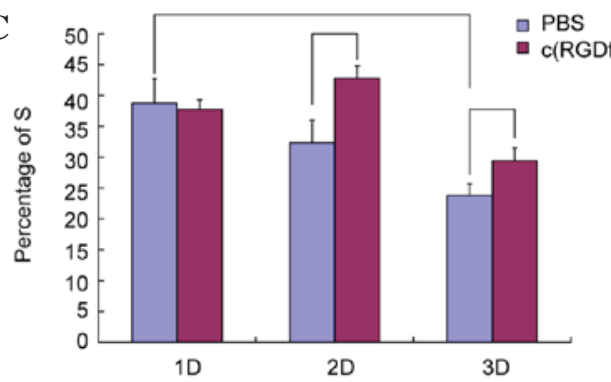

Figure 3. (A) c(RGDfV) affects the leukemia cell cycle. The stromal cells promoted the MV4-11 cells to stay at the stationary phase ( $<<0.05)$. $c($ RGDfV) exhibited little effect on the cell cycle of the MV4-11 cells without osteoblasts, while it promoted the leukemia cells to enter the cell cycle in the 3D and 2D culture systems. (B) c(RGDfV) decreased the G0/G1 phase of leukemia cells in the 3D and 2D culture systems. (C) c(RGDfV) increased the S phase of leukemia cells in the 3D and 2D culture systems. 1D, MV4-11 cells single culture; 2D, 2-dimensional; 3D, 3-dimensional; PBS, phosphate-buffered saline. "P<0.05.

A

PBS
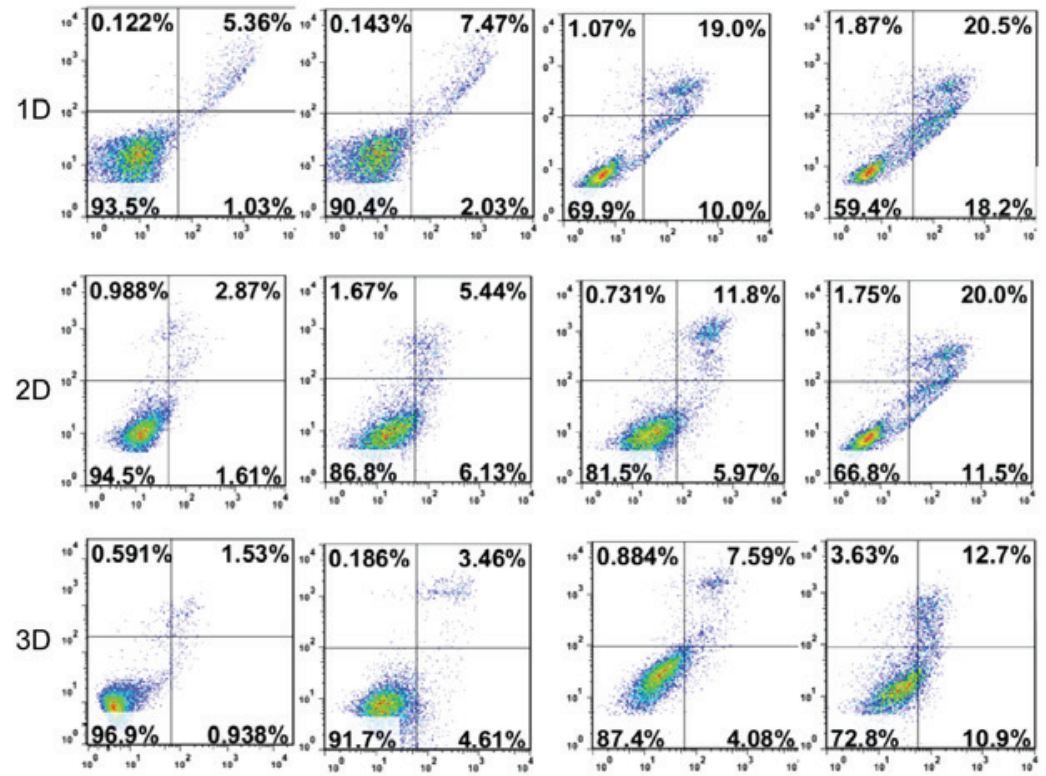

R+Ara-C
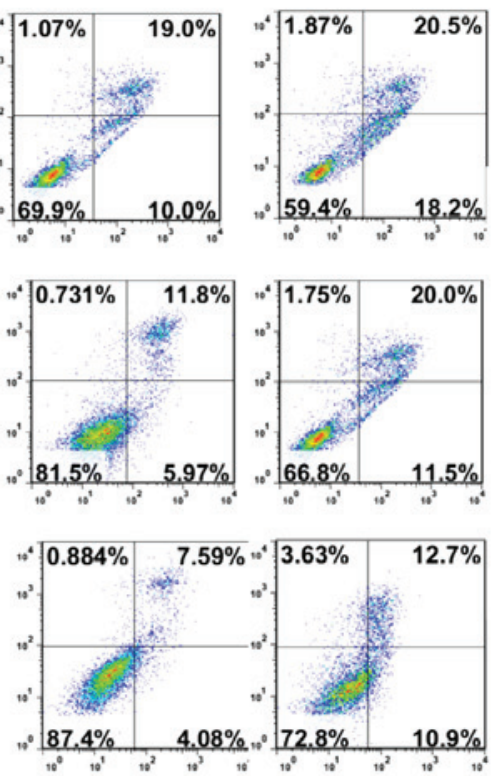

B

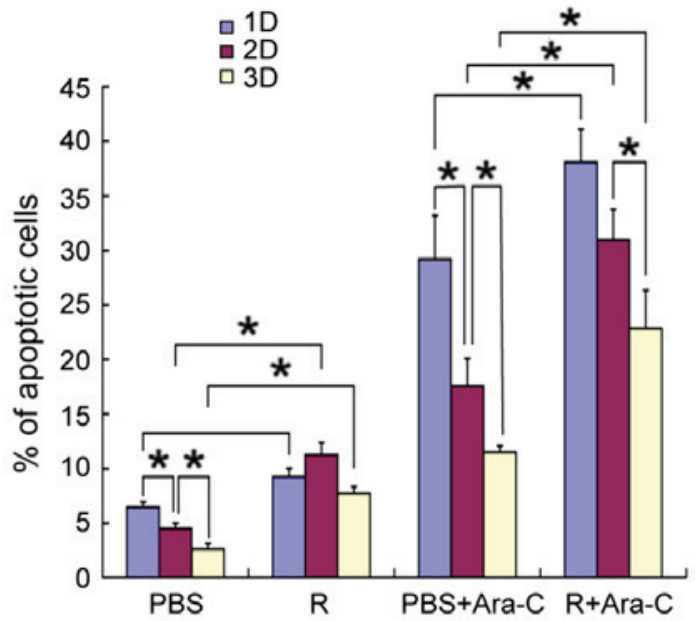

Figure 4. c(RGDfV) exhibits effects on leukemia cell apoptotic rates. (A) Original flow cytometry data. (B) Quantification showed that the percentage of apoptotic MV4-11 cells was lower in the presence of osteoblasts, which can enhance the drug resistance and antiapoptotic effect of leukemia cells. Osteoblasts also partially prevented Ara-C-induced apoptosis in the MV4-11 cells: following treatment with $0.2 \mu \mathrm{g} / \mathrm{ml} \mathrm{Ara-C}$, a high percentage of apoptosis occurred, while the apoptosis rate was lower in leukemia cells in the presence of bone marrow stromal cells. Ara-C, cytarabine; PBS, phophate-buffered saline; R, $c($ RGDfV). "P $<0.05$. 
from $6.46 \pm 0.5 \%$ when the leukemia cells and osteoblasts were cultured on the scaffolds compared with MV4-11 cells cultured alone $(\mathrm{P}<0.05)$. $\mathrm{c}(\mathrm{RGDfV})$ increased the apoptosis rates in the presence or absence of Ara-C when the leukemia cells were co-cultured with the osteoblasts. Prior to Ara-C being administrated in the scaffolds, the apoptosis rates induced by the c(RGDfV) and control groups were $7.71 \pm 0.63$ and $2.6 \pm 0.55 \%$, respectively. After Ara-C was administered, the apoptosis rates were $22.83 \pm 3.51$ and $11.52 \pm 0.56 \%$, respectively. In contrast to the $2 \mathrm{D}$ culture system, the scaffolds exhibited lower apoptosis rates and more leukemia cells were alive, which indicated that the $3 \mathrm{D}$ scaffolds had higher drug resistance and that the 3D culture system was favorable to cell growth (only the $0.2 \mu \mathrm{g} / \mathrm{ml}$ dosage of Ara-C is displayed, however, the other two doses exhibited similar effects). The experiments were repeated twice and produced identical results (Fig. 4).

\section{Discussion}

The bone marrow niche contains a large variety of cell types, including HSCs, MSCs, osteoblasts, macrophages, fat cells, reticular cells and endothelial cells, and it regulates stem cell quiescence, self-renewal and differentiation (9). Osteoblasts are the major compartments of the endosteal niche and they are differentiated from MSCs. Osteoblasts are bone-forming cells that play an important role in the osteoblastic niche (10). The endosteal niche resides under the endosteum. The area has a low level of oxygen and the HSCs maintain it in a quiescent state (low cycle or G0 phase) (11). In addition, the osteoblasts maintain the balance between HSC homing and trans-marrow migration $(12,13)$. Under the condition of normal hematopoiesis, the endosteal niche can support the long-term survival of HPCs and long-term culture-initiating cells (14).

To date, a large amount of 3D biological materials have been used to test whether they could promote the growth and osteogenic differentiation of MSCs. It was found that 3D Insert polystyrene (PS) scaffolds promoted the adhesion and growth of MSCs. Furthermore, they induced osteogenic differentiation with osteogenic supplements (15). The 3D PS scaffold relies on a solid polymer porous material. The scaffold possesses $100 \%$ pore interconnectivity. The cylinders are $150 \mu \mathrm{m}$ in diameter, with $200-\mu \mathrm{m}$ spaces between the fibers. The cultivation method for the $3 \mathrm{D}$ scaffolds is similar to that of the $2 \mathrm{D}$ culture system. In addition, it can enhance the efficiency of cell culture. Cytokines and growth factors secreted by cells are easy to separate. Cells can grow in the PS scaffolds in a relatively well distributed manner and they stick tightly to the scaffolds. The scaffolds are beneficial for cell adhesion and growth, and provide sufficient space and surface area for the secretion of extracellular matrix.

In the present study, a 3D bioengineered scaffold coated with leukemia osteoblasts was created. MSCs were employed and induced to differentiate into osteoblasts as feeder cells, and the $2 \mathrm{D}$ and $3 \mathrm{D}$ culture system was constructed to imitate the endosteal niche. In the experiments, the induced MSCs were identified as osteoblasts according to their morphology and expression of ALP. This showed that a biomimetic osteoblast niche had successfully been constructed. Next, a leukemia cell line was inoculated in it and the cells grew in the mimicked microenvironment. It was found that the scaffolds could promote cell proliferation. After 14 days of culture, the cell number had reached its maximum, which may be a result of the little remaining space for the growth of the cells. Compared with the 2D culture system, the cells possessed more viability, more extracellular matrix and longer proliferation periods in the $3 \mathrm{D}$ scaffold. The 3D Inserts increased the surface area and space for cell adhesion and growth compared with the 2D system. For example, the growth surface of the 3D Insert-PS 24 -well was $10.2 \mathrm{~cm}^{2}$, while the 2D surface was $1.9 \mathrm{~cm}^{2}$. The scaffolds offer a large number of cell binding sites and space for cell growth. 3D bioengineered scaffolds caused the osteoblasts to form an elongated, highly branched morphology, while the osteoblasts in the $2 \mathrm{D}$ system were flat in shape.

The abilities of the leukemia osteoblasts to decrease the apoptosis rate and their effects on the cell cycle in the FLT3-ITD-positive myeloid leukemia MV4-11 cell line were then tested. From the scanning electron microscopy, it was apparent that the leukemia cells had adhered to the bone marrow stroma and gradually embedded in the bone marrow stromal layer to form a shelter structure. A few of the leukemia cells migrated to the marrow stromal layer and others penetrated into the cytoplasm, which constituted a shield phase association. In addition, the apoptotic leukemia cell rate was lower in the presence of the osteoblasts. It was also found that the co-culture of primary cultured leukemia osteoblasts and MV4-11 cells made the leukemia cells arrest in the G0/G1 phase. The bone marrow niche protected the stem cells from the deleterious effects of Ara-C. The leukemia microenvironment is believed to be a key factor of drug resistance. Resistance may be caused by the release of soluble growth factors or by cell-cell (16) or cell-extracellular matrix (17) interactions. Cell adhesion-mediated drug resistance is the resistance to chemotherapy caused by malignant cells with stroma. In AML, the bone marrow microenvironment offers a vital shelter of minimal residual disease following chemotherapy (18). These data suggest that stromal cells can protect the AML cells from the damage caused by chemotherapy drugs. The present results are consistent with these results and those of another previous study (19). Furthermore, the MV4-11 cells in the 3D system displayed higher percentages of G0/G1 phase cells and fewer apoptotic cells compared with the 2D culture system, indicating that the 3D system better represented in vivo drug resistance.

Osteopontin is a secreted phosphorylated glycoprotein that is synthesized and secreted by various tissues and cells. In the bone marrow, osteoblasts are the main cells to secrete Opn. When binding with its receptor ( $\alpha v \beta$ integrin family or CD44), Opn can mediate the adhesion between cells and stroma, and activate the second messengers of the signal transduction pathways. In addition, Opn can inhibit the apoptosis of cells (20). The levels of Opn in the tissue and blood are the indices of the diagnosis and prognosis of cancer. Lee et al (21) found that in newly diagnosed AML patients, the higher the Opn level the worse the prognosis. Opn is an independent adverse prognostic factor in AML. The high expression of Opn in the leukemia bone marrow niche is the pivotal factor for resistant and residual leukemia cells. Opn may act as a 'molecular switch' in the adhering and sheltering of AML cells by bone marrow microenvironment. In the present study, it was found that Opn was expressed in the niche.

Opn can combine with $\alpha v \beta 3$ and CD44, and regulate the expression of the downstream effector genes. The combination 
plays a key role in HSC adhesion and induces them to stay in the endosteal niche and maintain the G0 period $(22,23) . \alpha v \beta 3$ is a membrane receptor protein with a specially recognized RGD sequence (Arg-Gly-Asp). $\alpha v \beta 3$ is highly expressed in tumor cells, with low expression in normal cells, so it is an ideal target for tumor therapy. If there are RGD domain mutations, Opn will lose the function of promoting adhesion, and at the same time, it will induce the apoptosis of the cells (24). Mitjans et al (25) administered the antagonists of $\alpha v \beta 3$, namely $\alpha v \beta 3$-specific monoclonal antibody 17E6 and cyclic RGD peptide, to melanoma cells and found that each inhibited cell adhesion.

In the present study, $c($ RGDfV), which blocks $\alpha v \beta 3$, was administered, and it was found that this had no effect on the cell cycle when leukemia cells were cultured alone. However, c(RGDfV) caused additional effects to spontaneous and Ara-C-induced apoptosis in leukemia cells and induced the cells to pass the stationary phase in the presence of osteoblasts. Furthermore, the leukemia cells in the 3D and 2D culture systems showed similar effects. The 3D system also showed fewer apoptotic cells and a greater percentage of G0/G1 phase cells, which indicated that the 3D scaffolds possessed a greater percentage of drug resistance. The present study also tested the effects of $c($ RGDfV) on adhesion and migration. The results showed that the drug decreased adhesion and induced migration to the osteoblasts. Overall, $\mathrm{c}(\mathrm{RGDfV})$ may promote the leukemia cells to leave the protective endosteal niche and enhance their chemotherapeutic sensitivity.

In conclusion, the interaction of leukemia cells with the bone marrow niche provides a protective environment and resistance to chemotherapy agents such as Ara-C. An increasing amount of research is being focused on disrupting the interaction of leukemia cells and stromal cells to enhance the killing effect of chemotherapy drugs. c(RGDfV) can be used to mobilize leukemia cells through the disrupting the Opn/ $\alpha$ v 33 axis to make the myeloid leukemia cells more sensitive to chemotherapy agents. The present experiments indicated that such administration may be used to enhance the sensitivities to chemotherapy drugs by interfering with the adhesion between leukemia cells and the endosteal niche. Therefore, improving the hematopoietic microenvironment to clear minimal residual disease may be worthwhile and may provide a novel method for the treatment of leukemia. 3D scaffolds may also be a novel tool to study the hematopoietic microenvironment.

\section{Acknowledgements}

This study was supported by a grant from the National Natural Science Foundation, the Key Discipline of Medical Science of China (grant no. 81000195).

\section{References}

1. Schofield R: The relationship between the spleen colony-forming cell and the haemopoietic stem cell. Blood Cell 4: 7-25, 1978

2. Saito Y, Kitamura H, Hijikata A, Tomizawa-Murasawa M, Tanaka S, Takagi S, Uchida N, Suzuki N, Sone A, Najima Y, et al: Identification of therapeutic targets for quiescent, chemotherapy-resistant human leukemia stem cells. Sci Transl Med 2: 17ra9, 2010.

3. Lane SW, Scadden DT and Gilliland DG: The leukemic stem cell niche: Current concepts and therapeutic opportunities. Blood 114: 1150-1157, 2009.
4. Bissell MJ, Rizki A and Mian IS: Tissue architecture: the ultimate regulator of breast epithelial function. Curr Opin Cell Biol 15: 753-762, 2003.

5. Breslin S and O'Driscoll L: Three-dimensional cell culture: the missing link in drug discovery. Drug Discov Today 18: 240-249, 2013.

6. Nilsson SK, Johnston HM, Whitty GA, Williams B, Webb RJ, Denhardt DT, Bertoncello I, Bendall LJ, Simmons PJ and Haylock DN: Osteopontin, a key component of the hematopoietic stem cell niche and regulator of primitive hematopoietic progenitor cells. Blood 106: 1232-1239, 2005.

7. Kluza E, van der Schaft DW, Hautvast PA, Mulder WJ, Mayo KH, Griffioen AW, Strijkers GJ and Nicolay K: Synergistic targeting of alphavbeta3 integrin and galectin-1 with heteromultivalent paramagnetic liposomes for combined MR imaging and treatment of angiogenesis. Nano Lett 10: 52-58, 2010.

8. Kassem M, Risteli L, Mosekilde L, Melsen F and Eriksen EF: Formation of osteoblast-like cells from human mononuclear bone marrow cultures. APMIS 99: 269-274, 1991.

9. Locatelli F, Maccario R and Frassoni F: Mesenchymal stromal cells, from indifferent spectators to principal actors. Are we going to witness a revolution in the scenario of allograft and immune-mediated disorders? Haematologica 92: 872-877, 2007.

10. Mendez-Ferrer S, Michurina TV, Ferraro F, Mazloom AR, Macarthur BD, Lira SA, Scadden DT, Ma'ayan A, Enikolopov GN and Frenette PS: Mesenchymal and haematopoietic stem cells form a unique bone marrow niche. Nature 466: 829-834, 2010.

11. Eliasson P and Jönsson JI: The hematopoietic stem cell niche: Low in oxygen but a nice place to be. J Cell Physiol 221: 17-22, 2010.

12. Balduino A, Hurtado SP, Frazão P, Takiya CM, Alves LM, Nasciutti LE, El-Cheikh MC and Borojevic R: Bone marrow subendosteal microenvironment harbours functionally distinct haemosupportive stromal cell populations. Cell Tissue Res 319: 255-266, 2005

13. Visnjic D, Kalajzic Z, Rowe DW, Katavic V, Lorenzo J and Aguila HL: Hematopoiesis is severely altered in mice with an induced osteoblast deficiency. Blood 103: 3258-3264, 2004.

14. Calvi LM, Adams GB, Weibrecht KW, Weber JM, Olson DP, Knight MC, Martin RP, Schipani E, Divieti P, Bringhurst FR, et al: Osteoblastic cells regulate the haematopoietic stem cell niche. Nature 425: 842-846, 2003.

15. Rodríguez JP, González M, Ríos S and Cambiazo V: Cytoskeletal organization of human mesenchymal stem cells (MSC) changes during their osteogenic differentiation. J Cell Biochem 93: 721-731, 2004

16. Paraguassú-Braga FH, Borojevic R, Bouzas LF, Barcinski MA and Bonomo A: Bone marrow stroma inhibits proliferation and apoptosis in leukemic cells through gap junction-mediated cell communication. Cell Death Differ 10: 1101-1108, 2003.

17. Moqattash S and Lutton JD: Leukemia cells and the cytokine network. Proc Soc Exp Biol Med 219: 8-27, 1998.

18. Meads MB, Hazlehurst LA and Dalton WS: The bone marrow microenvironment as a tumor sanctuary and contributor to drug resistance. Clin Cancer Res 14: 2519-2526, 2008

19. Tabe Y, Konopleva M, Munsell MF, Marini FC, Zompetta C, McQueen $\mathrm{T}$, Tsao $\mathrm{T}$, Zhao S, Pierce S, Igari J, et al: PML-RARalpha is associated with leptin-receptor induction: The role of mesenchymal stem cell-derived adipocytes in APL cell survival. Blood 103: 1815-1822, 2004.

20. Hijiya N, Setoguchi M, Matsuura K, Higuchi Y, Akizuki S and Yamamoto S: Cloning and characterization on of the human osteopontin gene and its promoter. Biochem J 303: 255-262, 1994.

21. Lee CY, Tien HF, Hou HA, Chou WC and Lin LI: Marrow osteopontin level as a prognostic factor in acute myeloid leukemia. $\mathrm{Br}$ J Haematol 141: 736-739, 2008.

22. Nilsson SK, Johnston HM, Whitty GA, Williams B, Webb RJ, Denhardt DT, Bertoncello I, Bendall LJ, Simmons PJ and Haylock DN: Osteopontin, a key component of the hematopoietic stem cell niche and regulator of primitive hematopoietic progentior cells. Blood 106: 1232-1239, 2005.

23. Haylock DN and Nilsson SK: Osteopontin: A bridge between bone and blood. Br J Haematol 134: 467-474, 2006.

24. Courter D, Cao H, Kwok S, Kong C, Banh A, Kuo P, Bouley DM, Vice C, Brustugun OT, Denko NC, et al: The RGD domain of human osteopontin promotes tumor growth and metastasis through activation of survival pathways. PLoS One 5: e9633, 2010.

25. Mitjans F, Meyer T, Fittschen C, Goodman S, Jonczyk A, Marshall JF, Reyes $\mathrm{G}$ and Piulats J: In vivo therapy of malignant melanoma by means of antagonists of alphav integrins. Int $\mathrm{J}$ Cancer 87: 716-723, 2000. 